\title{
FLIPing heterokaryons to analyze nucleo-cytoplasmic shuttling of yeast proteins
}

\author{
KATSIARYNA BELAYA, DAVID TOLLERVEY, and MARTIN KOŠ \\ Wellcome Trust Centre for Cell Biology, University of Edinburgh, EH9 3JR, United Kingdom
}

\begin{abstract}
Nucleo-cytoplasmic shuttling is an important feature of proteins involved in nuclear export/import of RNAs, proteins, and also large ribonucleoprotein complexes such as ribosomes. The vast amount of proteomic data available shows that many of these processes are highly dynamic. Therefore, methods are needed to reliably assess whether a protein shuttles between nucleus and cytoplasm, and the kinetics with which it exchanges. Here we describe a combination of the classical heterokaryon assay with fluorescence recovery after photobleaching (FRAP) and fluorescence loss in photobleaching (FLIP) techniques, which allows an assessment of the kinetics of protein shuttling in the yeast Saccharomyces cerevisiae.
\end{abstract}

Keywords: nucleo-cytoplasmic shuttling; Saccharomyces cerevisiae

\section{INTRODUCTION}

Many analyses in yeast and higher eukaryotes have addressed the transport of factors between the nucleus and cytoplasm. However, previous assays for nucleo-cytoplasmic shuttling in yeast have either used a conventional heterokaryon assay (Flach et al. 1994) or changes in protein distribution in mutants defective in either import or export. Both of these approaches rely on assessments of the steady-state distribution of the protein, and therefore, do not allow the kinetics to be addressed. Moreover, yeast heterokaryon formation requires at least $1-2 \mathrm{~h}$, so de novo protein synthesis must be inhibited, either by placing the gene of interest under the control of regulated promoter (Flach et al. 1994; Peng and Hopper 2000) or by the use of protein synthesis inhibitors (Oeffinger et al. 2004). This can introduce artifacts due to either altered levels of protein expression or the general inhibition of translation. In addition, inhibition of translation severely affects heterokaryon formation (K. Belaya, D. Tollervey, and M. Koš, unpubl.). The use of FLIP or FRAP to assess nucleo-cytoplasmic shuttling has been reported in higher eukaryotes (for review, see Koster et al. 2005). However, the very small size of yeast cells has prevented the application of these techniques. We therefore sought to develop a new

Reprint requests to: Martin Koš, Wellcome Trust Centre for Cell Biology, University of Edinburgh, EH9 3JR, UK; e-mail: martin.kos@ ed.ac.uk; fax: 44-131-650-7040.

Article published online ahead of print. Article and publication date are at http://www.rnajournal.org/cgi/doi/10.1261/rna.2301806. approach, combining a heterokaryon assay with FRAP/FLIP to assess the shuttling properties of proteins in yeast.

\section{RESULTS}

To demonstrate the feasibility of the proposed approach, we decided to assess the shuttling properties of the ribosome synthesis factor Arxlp. Previous analyses identified Arxlp as a component of a late pre-60S ribosomes that were associated with putative export factors Nmd3p, Nug1p, and Nug2p (Bassler et al. 2001; Nissan et al. 2002). Arxlp was enriched in nucleus, but was also detected in cytoplasm. Together, these observations suggested, but did not formally demonstrate that Arxlp is a shuttling protein that accompanies the pre-60S particles during nuclear export (Nissan et al. 2002).

A strain expressing GFP-tagged versions of Arx1p was created. Arx1p is nonessential for viability, but $\operatorname{arx} 1 \Delta$ strains are mildly impaired in growth (data not shown). No growth impairment was seen in the $A R X 1:: G F P$ strain, indicting that the fusion construct is functional. The strain expressing Arx1-GFP was mated with a strain carrying the kar1-1 mutation, which prevents nuclear fusion following cell fusion, leading to formation of a heterokaryon with two nuclei. To reduce background fluorescence, mating was performed in complete synthetic medium.

We initially assessed the shuttling of Arxp1 in a conventional heterokaryon assay (Fig. 1). Arx1p-GFP was detected in both nuclei of heterokaryons $3 \mathrm{~h}$ after mating. In contrast, a known nonshuttling nucleolar protein GarlpGFP (Girard et al. 1992) was detected in only one nucleus 


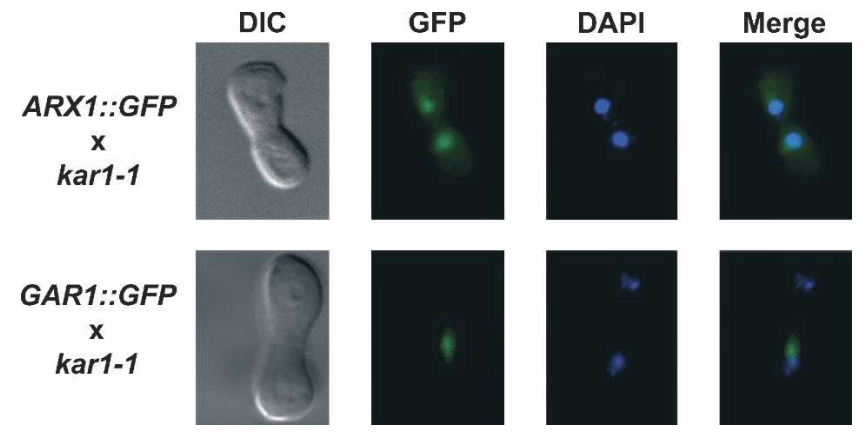

FIGURE 1. Heterokaryon assay. Cells expressing either Arxlp-GFP or Garlp-GFP were mated with karl-1 strain and placed on YPD plate containing cycloheximide to inhibit de novo protein synthesis. After a 2-h incubation, heterokaryons were analyzed by fluorescence microscopy for presence of GFP signal in both nuclei.

of the heterokaryon. This would be consistent with nuclearcytoplasmic shuttling of Arx1-GFP, but might simply result from uptake of the cytoplasmic pool of Arxlp, slow leakage of Arxlp from the "donor" (i.e., Arxl-GFP expressing) nucleus over the 3-h time course of the mating, or even a high level of de novo synthesis.

To allow a FRAP/FLIP analyses, one nucleus of the heterokaryon was completely bleached. Recovery of fluorescence in the target nucleus (FRAP) and loss of fluorescence in the unbleached nucleus (FLIP) were then followed in real time. To increase the resolution of the analysis, we repeated the bleaching of the target nucleus up to four times, after which the fluorescent signal in the unbleached nucleus was largely lost (Fig. 2A). The recovery of fluorescence in the bleached nucleus was approximately reciprocal to the loss of fluorescence in the unbleached nucleus, demonstrating rapid exchange of Arx1-GFP between both nuclei. The fluorescence of unbleached control nuclei in nearby cells was only mildly decreased by general photobleaching of the sample during viewing.

To control for de novo protein synthesis and recovery of nuclear signal from the cytoplasmic pool of Arxlp, we bleached both nuclei of a heterokaryon and followed the recovery of nuclear fluorescence (Fig. 2B). Little photo-recovery

\section{A}

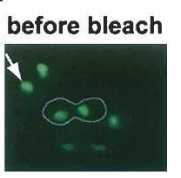

bleach 2
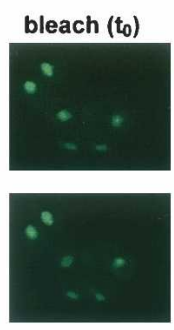

bleach 3

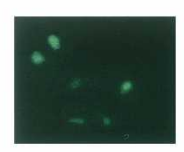

bleach 4

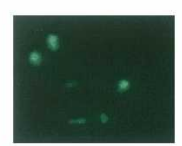

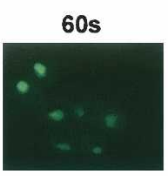
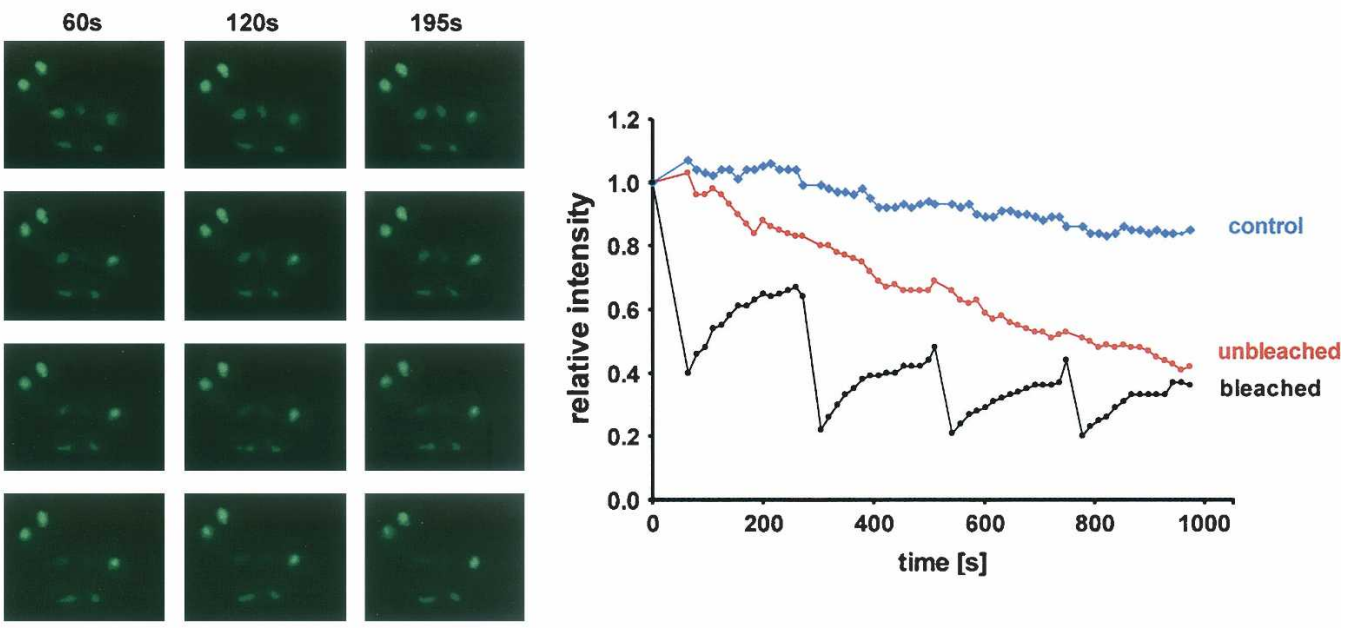

B
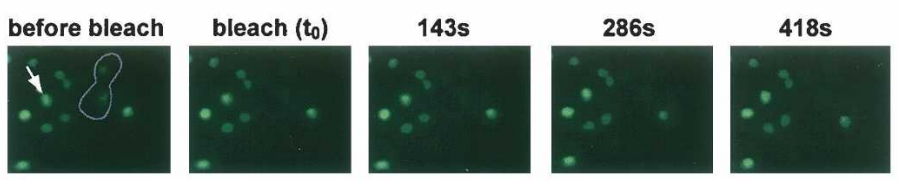

FIGURE 2. Arxlp shuttles rapidly between nucleus and cytoplasm. (A) One nucleus of a heterokaryon (outlined) expressing Arxlp-GFP was bleached four times every $225 \mathrm{sec}$. The fluorescence intensity in both nuclei was recorded at 15 -sec time points (graph on the right). A representative set of frames is shown. An arrow indicates the control nonbleached nucleus in a neighboring cell. (B) To control for cytoplasmic pool of Arxlp-GFP and de novo protein synthesis, both nuclei of heterokaryon were bleached and fluorescence intensity in both nuclei was followed by an 11-sec interval. 
was seen in either nucleus, showing that neither the cytoplasmic pool nor de novo synthesis of Arxlp contributed significantly to the fluorescence recovery in cells with a single bleached nucleus.

These observations demonstrate that Arxlp is a bona fide nucleo-cytoplasmic shuttling protein. Moreover, the kinetics of recovery/loss of fluorescence can be also used to estimate the flux of Arx1p. Figure 3A shows recovery and loss of fluorescence after the first bleach in two independent "multibleach" experiments. Figure 3B shows fluorescence recovery and loss in a heterokaryon after single bleach, which was followed for $5 \mathrm{~min}$ to allow complete equilibration of the signals in unbleached and bleached nucleus. Exponential curves were fitted to the obtained data. The shuttling half life can be calculated from the fitted exponential function $\left(y=a \cdot e^{-b x}\right)$ as $t_{1 / 2}=\ln 2 / b$. The average value, calculated from eight independent experiments, was $11.2 \pm 1.3 \mathrm{~min}$. If the cytoplasmic protein has an equal chance of reimport into either nucleus, the flux of export is double this value. The half life of nuclear Arxlp is therefore $\sim 5.6 \mathrm{~min}$.

\section{DISCUSSION}

This study shows that FLIP/FRAP photobleaching techniques can be applied to yeast heterokaryons to measure kinetics of a protein shuttling. The method described here overcomes the limitation of the small size of yeast cells and allows characterization of proteins without interfering with their expression levels. Moreover, it does not require additional positive or negative controls, and thus circumvents problems with differing strain backgrounds and reduces the number of samples. The recently described photo-activated fluorescent proteins (Lukyanov et al. 2005) may provide useful variations of the technique described here. The kinetic data can provide valuable information about protein function.
From the data obtained we estimate that the nuclear pool of Arxlp is exchanged with the cytoplasmic pool with a half life of $\sim 5.5 \mathrm{~min}$. The abundance of Arx1p was estimated from large-scale affinity purification studies at 45,000 molecules per cell (Ghaemmaghami et al. 2003). As shown in Figure 1, Arxlp is predominantly nuclear, and thus the shuttling rate of Arxlp is $\sim 4000$ molecules per minute. This figure is in excess over the estimated ribosome synthesis rate of $\sim 2000$ ribosomes per minute (Warner 1999). It is possible that more than one molecule of Arxlp is exported per ribosome. Alternatively, Arxlp might participate in other export pathways. We have observed an apparent defect in pre-tRNA maturation in strains lacking Arxlp (data not shown), but it is currently unclear whether this reflects impaired pre-tRNA export.

The technique we describe overcomes many limitations of the conventional heterokaryon assay in yeast and should be of use in analyses of many other nuclear-cytoplasmic shuttling factors.

\section{MATERIALS AND METHODS}

\section{Yeast strains and plasmids}

Strains and plasmids used in this study are listed in Table 1. All strains were handled as described (Guthrie and Fink 1991).

\section{Heterokaryon assay}

The classical assay was done as described in Flach et al. (1994) and Peng and Hopper (2000) with modifications. Briefly, cells were grown in synthetic complete medium until $\mathrm{OD}_{600} \sim 1$. The mating was initiated by mixing $1 \mathrm{~mL}$ of $A R X 1:: G F P$ (D912) or Gar1-GFP expressing cells (YKB2) with kar1-1 strain (D660). Cells were concentrated by filtration onto $25-\mathrm{mm}, 0.45-\mathrm{mm}$ nitrocellulose filters and then placed onto YPD plate. Cells were monitored visually and after $\sim 40 \mathrm{~min}$, when first heterokaryons started to appear, the filters were placed on YPD plate containing $50 \mu \mathrm{g} / \mathrm{mL}$
A

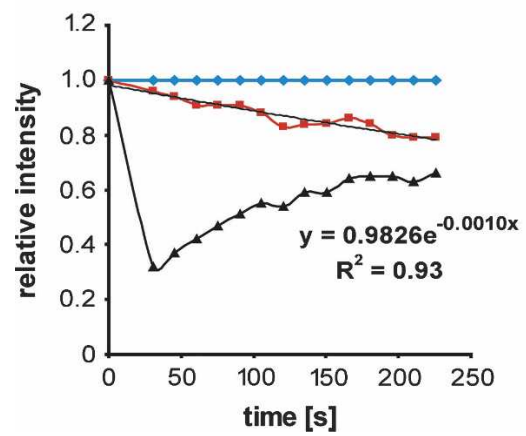

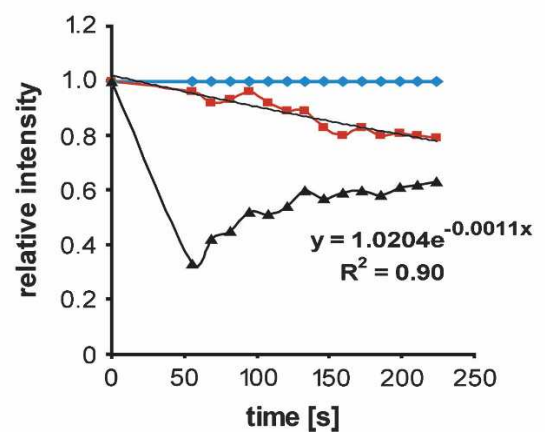

B

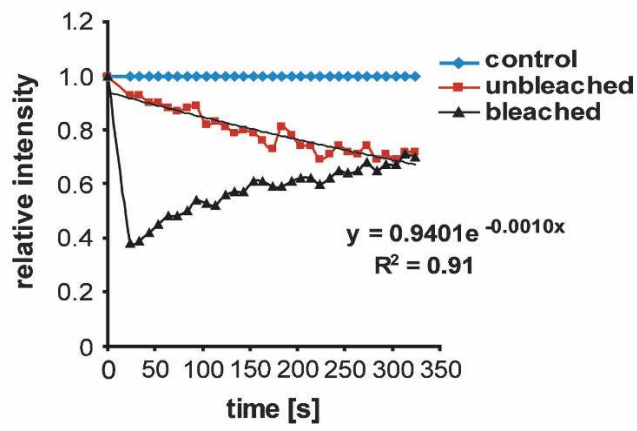

FIGURE 3. Kinetics of Arxlp shuttling. (A) Graphs representing the fluorescence loss and recovery in the heterokaryon nuclei during the first bleach from two independent experiments. The fluorescence intensity was normalized to the intensity in the control nucleus. An exponential curve was fitted to the nonbleached nucleus and the calculated exponential function and correlation coefficient are shown. (B) As in $A$, but the heterokaryon was bleached only once and the fluorescence loss and recovery were followed until complete equilibration of the intensity in both nuclei. 
TABLE 1. Yeast strains and plasmids used in this study

\begin{tabular}{|c|c|c|}
\hline Strain & Genotype & Reference \\
\hline D660 & MATa; ura3-52; leu2-3,112; kar1-1 & Vallen et al. (1992) \\
\hline D897/898 $(\operatorname{arx} 1 \Delta)$ & $\mathrm{MATa} / \alpha$; his $3 \Delta 1$; leu2 $\Delta 0$; met15 $\Delta 0$; ura3 $\Delta 0$; YDR101c::KanMX4 & Euroscarf Y04036 \\
\hline D912 & MAT $\alpha$; ura3; trp1; leus2; ARX1::GFP-HIS3MX6 & Nissan et al. (2002) \\
\hline YKB2 & D898 but with pZNT3-Gar1-GFP & This study \\
\hline Plasmid & Description & Reference \\
\hline pZNT3-Gar1-GFP & CEN plasmid expressing Gar1-GFP & Trumtel et al. (2000) \\
\hline
\end{tabular}

cycloheximide and incubated for another $2 \mathrm{~h}$. Cells were washed off the membrane and fixed in $4 \%(\mathrm{v} / \mathrm{v})$ formaldehyde and analyzed by microscopy (Leica HC).

For FLIP/FRAP experiments, the cells were grown in SD complete medium, mixed for mating with kar1-1 strain, and deposited on a filter, which was placed on a plate for $3 \mathrm{~h}$. Then, cells were washed and spotted on a thin layer of $2 \%$ agarose in SD medium (growth chamber) on a slide. Fluorescence time-lapse imaging was performed on Zeiss Axiovert 200M microscope at room temperature. For bleaching, a 377-nm Nitrogen pulse laser (Photonics Instruments) was used. A nucleus of a heterokaryon was photobleached by a $10-\mathrm{msec}$ pulse and a single focal plane with $400 \mathrm{msec}$ exposure time was recorded every $15 \mathrm{sec}$ (11 sec for the experiment with both nuclei of heterokaryon bleached). Fluorescence of the regions of interest was quantified at each time point using SlideBook 4.0 software. Mean fluorescence was calculated as intensity per area and normalized to the level before photobleaching.

\section{ACKNOWLEDGMENTS}

We thank Kevin Hardwick and Karen May for their help with photobleaching techniques. K.B. was supported by the Darwin Trust, D.T. was supported by the Wellcome Trust, and M.K. was supported by an EU Marie Curie Fellowship MEIF-CT-2003-501083.

Received November 27, 2005; accepted January 18, 2006.

\section{REFERENCES}

Bassler, J., Grandi, P., Gadal, O., Lessmann, T., Petfalski, E., Tollervey, D., Lechner, J., and Hurt, E. 2001. Identification of a $60 \mathrm{~S}$ preribosomal particle that is closely linked to nuclear export. Mol. Cell 8: 517-529.
Flach, J., Bossie, M., Vogel, J., Corbett, A., Jinks, T., Willins, D.A., and Silver, P.A. 1994. A yeast RNA-binding protein shuttles between the nucleus and the cytoplasm. Mol. Cell. Biol. 14: 83998407.

Ghaemmaghami, S., Huh, W.K., Bower, K., Howson, R.W., Belle, A., Dephoure, N., O'Shea, E.K., and Weissman, J.S. 2003. Global analysis of protein expression in yeast. Nature 425: 737-741.

Girard, J.P., Lehtonen, H., Caizergues-Ferrer, M., Amalric, F., Tollervey, D., and Lapeyre, B. 1992. GAR1 is an essential small nucleolar RNP protein required for pre-rRNA processing in yeast. EMBO J. 11: 673-682.

Guthrie, C. and Fink, G.R. 1991. Methods in enzymology: Guide to yeast genetics and molecular biology. 194. Academic Press, NY.

Koster, M., Frahm, T., and Hauser, H. 2005. Nucleocytoplasmic shuttling revealed by FRAP and FLIP technologies. Curr. Opin. Biotechnol. 16: 28-34.

Lukyanov, K.A., Chudakov, D.M., Lukyanov, S., and Verkhusha, V.V. 2005. Innovation: Photoactivatable fluorescent proteins. Nat. Rev. Mol. Cell Biol. 6: 885-891.

Nissan, T.A., Bassler, J., Petfalski, E., Tollervey, D., and Hurt, E. 2002. 60 S pre-ribosome formation viewed from assembly in the nucleolus until export to the cytoplasm. EMBO J. 21: 55395547.

Oeffinger, M., Dlakic, M., and Tollervey, D. 2004. A pre-ribosomeassociated HEAT-repeat protein is required for export of both ribosomal subunits. Genes \& Dev. 18: 196-209.

Peng, G. and Hopper, J.E. 2000. Evidence for Gal3p's cytoplasmic location and Gal80p's dual cytoplasmic-nuclear location implicates new mechanisms for controlling Gal4p activity in Saccharomyces cerevisiae. Mol. Cell. Biol. 20: 5140-5148.

Trumtel, S., Leger-Silvestre, I., Gleizes, P.E., Teulieres, F., and Gas, N. 2000. Assembly and functional organization of the nucleolus: Ultrastructural analysis of Saccharomyces cerevisiae mutants. Mol. Biol. Cell 11: 2175-2189.

Vallen, E.A., Hiller, M.A., Scherson, T.Y., and Rose, M.D. 1992. Separate domains of KAR1 mediate distinct functions in mitosis and nuclear fusion. J. Cell Biol. 117: 1277-1287.

Warner, J.R. 1999. The economics of ribosome biosynthesis in yeast. Trends Biochem. Sci. 24: 437-440. 

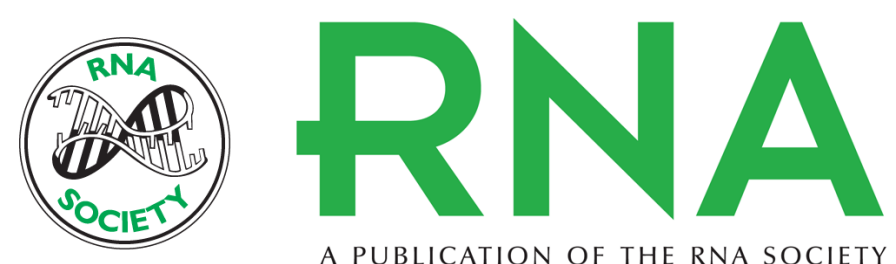

A PUBLICATION OF THE RNA SOCIETY

\section{FLIPing heterokaryons to analyze nucleo-cytoplasmic shuttling of yeast proteins}

Katsiaryna Belaya, David Tollervey and Martin Kos

RNA 2006 12: 921-930

References This article cites 12 articles, 6 of which can be accessed free at: http://rnajournal.cshlp.org/content/12/5/921.full.html\#ref-list-1

\section{License}

Email Alerting Receive free email alerts when new articles cite this article - sign up in the box at the Service top right corner of the article or click here. 